\title{
The Large Focal Isolated Chondral Lesion
}

\author{
Jorge Chahla, MD, PhD ${ }^{1}$ Brady T. Williams, MD $^{2}$ Adam B. Yanke, MD, PhD ${ }^{1}$ Jack Farr ${ }^{3}$ \\ ${ }^{1}$ Department of Orthopedic Surgery, Rush University Medical Center, \\ Chicago, Illinois \\ 2 Department of Orthopedic Surgery, University of Colorado, Aurora, \\ Colorado \\ ${ }^{3}$ Knee Preservation and Cartilage Restoration Center, Ortholndy,

\begin{abstract}
Address for correspondence Jorge Chahla, MD, PhD, Department of Orthopedic Surgery, Rush University Medical Center, 1611 W Harrison Street, Suite 300, Chicago Excelsior, IL 55331

(e-mail: jorge.chahla@rushortho.com).
\end{abstract} Indianapolis, Indiana

J Knee Surg 2023;36:368-381.

\author{
Abstract \\ Keywords \\ - cartilage \\ - focal chondral defect \\ - osteochondral \\ - knee \\ - regenerative
}

Focal chondral defects (FCDs) of the knee can be a debilitating condition that can clinically translate into pain and dysfunction in young patients with high activity demands. Both the understanding of the etiology of FCDs and the surgical management of these chondral defects has exponentially grown in recent years. This is reflected by the number of surgical procedures performed for FCDs, which is now approximately 200,000 annually. This fact is also apparent in the wide variety of available surgical approaches to FCDs. Although simple arthroscopic debridement or microfracture are usually the first line of treatment for smaller lesions, chondral lesions that involve a larger area or depth require restorative procedures such as osteochondral allograft transplantation or other cell-based techniques. Given the prevalence of FCDs and the increased attention on treating these lesions, a comprehensive understanding of management from diagnosis to rehabilitation is imperative for the treating surgeon. This narrative review aims to describe current concepts in the treatment of large FCDs through providing an algorithmic approach to selecting interventions to address these lesions as well as the reported outcomes in the literature.
Treatment of large articular cartilage defects of the knee can be difficult, particularly in young athletic patients. Such lesions are common in young individuals ( $<40$ years), with an overall incidence of 4.2 to $6.2 \%$, and up to $36 \%$ in athletes. ${ }^{1-5}$ In a series of nearly 1,000 arthroscopies, fullthickness cartilage defects meeting criteria for repair were found in $11 \%$ of knees, with $55 \%$ of lesions being greater than $2 \mathrm{~cm}^{2}{ }^{2}$ If left unaddressed, cartilage defects can worsen over time and may progress to diffuse degenerative changes. ${ }^{6}$ Surgical management of larger FCDs has evolved over the last decade with the advent of improved biotechnology and surgical techniques to address FCDs with promising outcomes reported in the literature. In particular, there has been a shift toward reparative and regenerative procedures in an effort to restore cartilage, improve patient symptoms, and reduce morbidity.

received

December 27, 2019

accepted after revision

June 25,2020

article published online

September 10, 2021

Currently, several procedures are considered when treating large FCDs $\left(>2.5 \mathrm{~cm}^{2}\right)$ that have demonstrated favorable and reproducible outcomes. ${ }^{7-16}$ Commonly employed procedures include osteochondral allograft transplantation (OCA), matrix-induced autologous chondrocyte implantation (MACI/ACI), minced cartilage procedures, cryopreserved osteochondral surface allografts, and augmented marrow stimulation in combination with extracellular matrix scaffolds. Given the array of treatment options, the challenge lies in determining which intervention or combination of interventions is most appropriate given patient- and defectspecific characteristics, while considering important comorbidities such as mechanical alignment, meniscal pathology, and ligamentous stability.

The purpose of this narrative review is to describe current concepts in the treatment of large FCDs, providing an

(c) 2021. Thieme. All rights reserved. Thieme Medical Publishers, Inc., 333 Seventh Avenue, 18th Floor, New York, NY 10001, USA
DOI https://doi.org/ 10.1055/s-0041-1735278. ISSN 1538-8506. 
algorithmic approach to selecting interventions to address these lesions along with reviewing the reported outcomes in the literature. In addition, both conservative and surgical approaches to the treatment of these defects are described, as well as recommended postoperative rehabilitation.

\section{Diagnosis}

Given the progressive nature of these lesions, successful treatment of FCDs is predicated on diagnosis early in the disease process to provide a window of opportunity for intervention. Early diagnosis can allow for more treatment options to restore articular surfaces, contact pressures, and kinematics. In addition to the timing of the diagnosis, it is equally important to establish an etiology to prevent progression and recurrence insofar as it is able to be addressed (e.g., weight loss, repairable meniscal tears, ligament injury, and malalignment). Missed or delayed diagnoses can potentially have significant consequences on patient function and quality of life, as symptoms continue to progress, possibly contributing to downstream osteoarthritis (OA). ${ }^{17,18}$ To ensure accurate and timely diagnosis, clinicians must perform a comprehensive assessment including a thorough history and physical exam, radiographs, and magnetic resonance imaging (MRI) when indicated.

\section{Patient History}

Evaluation of a patient with knee pain begins with a thorough patient history including a detailed characterization of the pain and associated symptoms, historic and present activity level, prior injuries, and any previous treatments. Pain and swelling are the most common presenting symptoms in patients with FCDs. Details of the pain, including onset, location, and associated symptoms can lend insight into the underlying diagnosis. For example, gradual onset is more commonly seen in conditions such as osteochondritis dissecans, while sudden onset pain is more commonly seen in acute injury and trauma. Although it should be noted that an acute traumatic event may not be the cause of the FCD, but rather the provocative event that uncovered a previously asymptomatic FCD.

Intuitively, the location of the pain and the corresponding position of the knee helps identify the site of injury. Pain is often localized to the affected compartment with joint loading, which is distinct from the diffuse pain secondary to progressive osteoarthritis and synovitis. For patients with patellofemoral FCDs, pain is typically anterior, but can also include retro- and peripatellar pain, and even popliteal-area pain in the case of trochlear defects. Since the cartilage itself lacks innervation, it is thought that the pain is a summation of inputs from a variety of sources, including synovial inflammation and overloading of the subchondral bone. ${ }^{19}$

In addition to current activity limitations, history should include a detailed account of a patient's prior activities. Participation in athletics and injuries should be elicited, given that sport is a common inciting and exacerbating activity. ${ }^{1,2,20}$ A systematic review of the literature reported a prevalence of full-thickness chondral defects in more than one-third of athletes identified. ${ }^{1}$ In addition to providing clues to the mechanism and location of injury, prior activities may also help identify patient-specific goals of treatment. Lastly, it is important to know what has been done before including prior injections, surgeries, and physical therapy.

\section{Physical Exam}

Patients with FCDs often do not have specific physical exam findings. Regardless, a systematic approach should be taken to ensure thorough assessment including inspection and palpation, range of motion, ligamentous stability, alignment, including gait and patellar tracking, and manual or instrumented strength assessment. ${ }^{21}$ Inspection and palpation may reveal varying degrees of swelling, joint effusions, and joint line tenderness, which may often be more pronounced over the lesion itself. Ligamentous stability of the knee is important to assess as ligament injury or gross laxity may be contributing to altered kinematics and cartilage loading. Similarly, mechanical alignment, gait analysis, rotational deformity, and muscular imbalance can also provide valuable information with respect to cartilage loading and potential lesion locations. Gait patterns can provide additional clues as to the location of lesions, including intoeing and abductor weakness in patellofemoral FCDs.

\section{Imaging}

Although physical exam findings can be suggestive of FCDs, imaging is required to determine the location and severity of these lesions. Imaging begins with weight-bearing plain radiographs to evaluate alignment and degenerative changes. Most commonly, views include standing full length anteroposterior films from the hip to the ankle, lateral and patellofemoral sunrise views of the knee, anteroposterior projections in full extension, and posteroanterior views in flexion. ${ }^{22}$ Lesions are not best visualized on X-ray, although some lesions, such a larger osteochondritis dissecans (OCD) lesions, are often visible on plain films. However, plains films provide additional valuable information regarding degenerative changes and mechanical alignment that may require surgical correction. ${ }^{23}$ Properly calibrated radiographs can also be used for preoperative planning of meniscal transplants to ensure correct size-matching of allografts. ${ }^{24}$

Magnetic resonance imaging is useful for the evaluation of articular cartilage and subchondral bone. However, clinicians should be aware that MRI findings can be misleading, both underestimating the size of the lesion and often failing to correlate with clinical symptoms. ${ }^{25,26}$ To more completely evaluate the articular cartilage, additional MR imaging techniques have been developed. These techniques include T2 mapping and delayed gadolinium-enhanced MRI of cartilage (dGEMRIC). Both techniques are useful in assessing specific biochemical properties of cartilage with biomechanical implications. T2 mapping provides quantitative data that can be used to measure collagen content, which may provide applications for postoperative evaluation for both quantity and quality of defect filling. ${ }^{27-29}$ In contrast, dGEMRIC is used to measure glycosaminoglycan content, which can be used to assess compressive stiffness of cartilage. ${ }^{27,30-32}$ 


\section{Role of Arthroscopy}

Although patient history, physical exam, and imaging can be supportive of the diagnosis, arthroscopy remains the gold standard for diagnosing the size and depth of FCDs. During arthroscopy, the depth can be reported by using one of several cartilage grading scales, the most common being the International Cartilage Repair Society (ICRS) and Outerbridge Criteria. In addition to being diagnostic, arthroscopy can be therapeutic, allowing for simultaneous debridement of unstable lesions and treatment of other intra-articular pathology, such as meniscal tears, that may also contribute to the symptomatology.

\section{Treatment}

\section{Conservative Management}

Debate exists surrounding the role of conservative and symptomatic management of FCDs given the possible progressive nature of such lesions. Patients may report symptomatic relief from a variety of medications and injections including nonsteroidal anti-inflammatory drugs, over the counter supplements (glucosamine and chondroitin), intraarticular injections (corticosteroids and hyaluronic acid), and biologics (platelet rich plasma and bone marrow aspirate concentrate). Activity modification, weight loss, strengthening and physical therapy, and bracing may also improve symptoms. The long-term implications of conservative management are still largely unknown given that the rapidity of progression is unclear. Several studies have looked at the treatment of OCD lesions and the impact of fragment removal, effectively creating a focal cartilage defect. Following removal, Shelbourne et al demonstrated good function and outcomes at midterm follow-up. However, joint space nar- rowing and symptoms were not reliably predicted based on factors such as defect size. ${ }^{33}$ Other case series following debridement and fragment removal have demonstrated a range of outcomes, including inconsistencies between patient reported function and evidence of progression. For example, Murry et al reported on long-term outcomes on a series of 32 knees, in which the overall mean American Knee Society Score (179) was indicative of good clinical function. Yet, radiographic evidence of early degenerative joint disease was present in more than $70 \%$ of patients at long-term follow-up (>11 years). ${ }^{34}$ It was noted that smaller lesions, stable (fragment preserved), and medial condyle lesions had better prognoses.

Review of the FCD literature reveals similar trends of progression. A recent systematic review of patients with untreated FCDs reported that patients were more likely to experience progression of cartilage damage; however, radiographic evidence of $\mathrm{OA}$ was not uniformly evident within 2 years of follow-up. ${ }^{18}$ Beyond 2 years, limited data exist. Messner and Maletius reported on long-term outcomes (14year follow-up) on a small series of athletes with radiographic confirmation of isolated chondral lesions. Despite the majority (78.6\%) of patients reporting good knee function, more than half of the patients demonstrated radiographic progression, with $42.9 \%$ demonstrating a reduction in joint space. ${ }^{35}$ This is in line with a growing body of evidence supporting surgical intervention of symptomatic FCDs to prevent progression of both symptoms and cartilage degeneration, with the goal of delaying or preventing the need for subsequent arthroplasty procedures. ${ }^{33,35-37}$ However, limited and conflicting data exist regarding the development or progression of radiographic evidence of osteoarthritis following cartilage procedures. ${ }^{38-45}$

\section{FOCAL CHONDRAL DEFECT ALGORITHM}

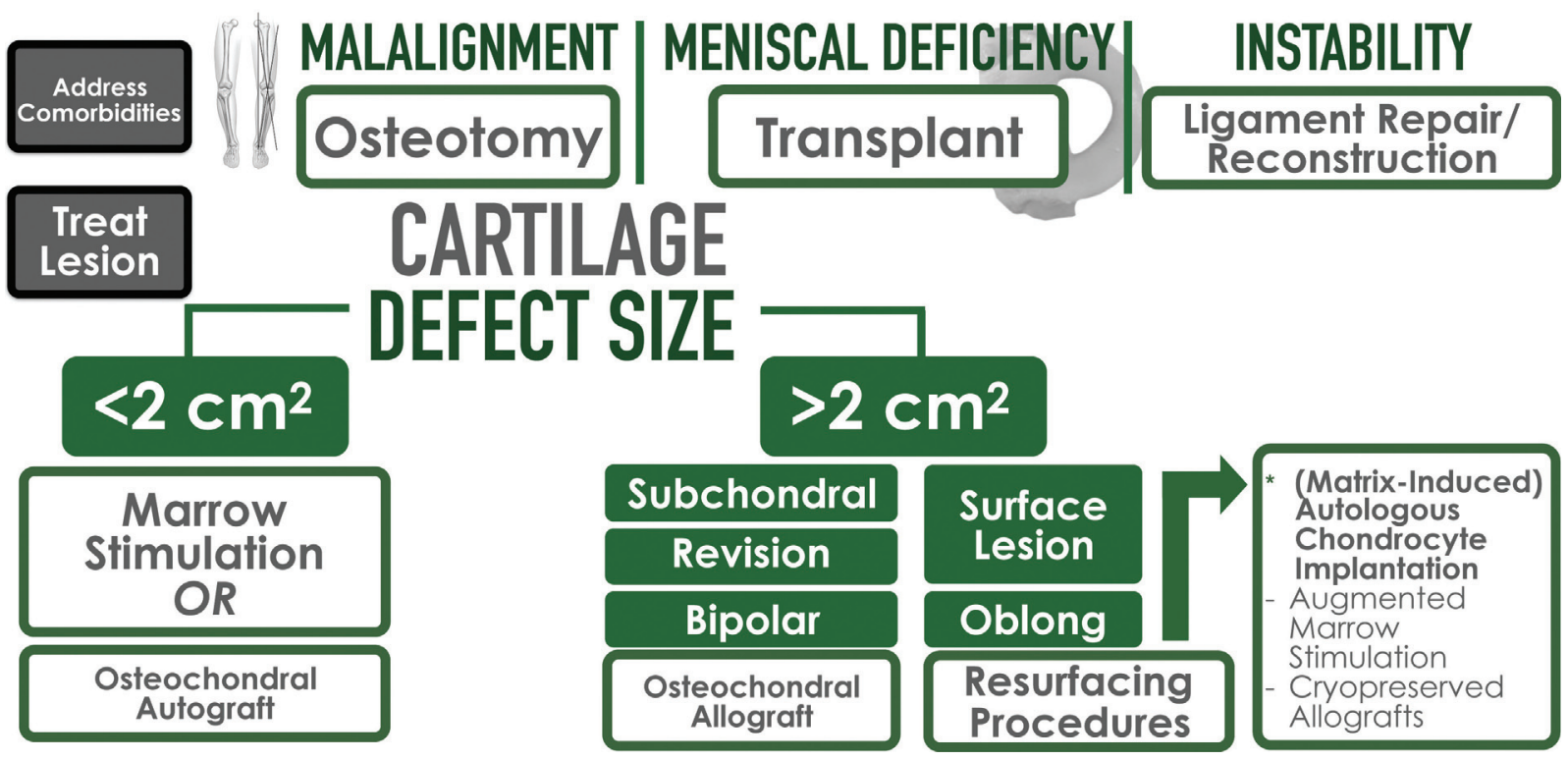

Fig. 1 Treatment algorithm outlining concurrent pathology and lesion specific characteristics and their impact on surgical decision-making and treatment options for focal chondral defects. 


\section{Surgical Treatment}

The goal of surgical treatment of FCDs is anatomic restoration of the joint surface and subchondral bone, to recreate normal biomechanical loading and contact pressures across the joint. The surgical intervention is determined based on the size, depth, location of the lesion, and other patient factors (-Fig. 1). However, when deciding on a surgical intervention, the constellation of concurrent knee pathology specific to each patient must factor into the treatment algorithm. This includes malalignment, concomitant meniscal pathology, and ligamentous injury, all of which can be addressed simultaneously in single stage procedures. In the case of meniscal pathology, studies to date confirm that cartilage procedures, such as osteochondral allograft transplantation and autologous chondrocyte implantation, can be performed in combination with meniscus allograft transplantation, with reliable results comparable to isolated cartilage procedures. ${ }^{46-49}$ Similarly, mechanical axis malalignment can be addressed with the appropriately indicated osteotomy to correct joint loading profiles and contact pressures. ${ }^{50}$ The importance of concurrently correcting alignment has been demonstrated both by improved outcomes in patients who were treated with single stage proximal tibial osteotomy (PTO) and cartilage procedures, and inferior outcomes in patients where malalignment was not addressed. ${ }^{51,52}$ Similarly, patellar FCDs with evidence of maltracking can also be simultaneously corrected with anteromedializing transfer of the tibial tuberosity. ${ }^{53,54}$ Lastly, any ligamentous pathology or laxity must be considered and corrected to restore knee kinematics and optimize the survivorship of any cartilage procedure. Perhaps the most well-documented example of this is the interplay of anterior cruciate ligament $(\mathrm{ACL})$ reconstruction and cartilage procedures. Wang et al compared ACL-reconstructed and ACLintact patients following OCA procedures, reporting no significant differences at 2 years. ${ }^{55}$ Following comprehensive consideration and plans for correction of these contributing factors, attention can then be turned to the FCD lesion itself.

A range of treatment options exist for FCDs that are dictated based on lesion specific factors including size, depth, and location, in addition to patient characteristics such as age, activity level, symptomatology, compliance, and patient preference. In the context of large FCDs $\left(>2.5 \mathrm{~cm}^{2}\right)$, many of the options that exist for smaller lesions $\left(<2 \mathrm{~cm}^{2}\right)$, such as debridement, abrasion arthroplasty, microfracture, and subchondral drilling, are not viable options. Larger lesions are more appropriately treated with osteochondral allograft transplantation (OCA), matrix-induced autologous chondrocyte implantation ( $\mathrm{MACI} / \mathrm{ACI}$ ), minced cartilage procedures, cryopreserved osteochondral surface allografts, and augmented marrow stimulation with extracellular matrix scaffolds.

\section{Osteochondral Allograft}

Osteochondral allografting is a widely used technique for treatment of a variety of chondral defects of the femoral condyles, trochlea, or patella either as primary treatment or as a revision procedure for prior cartilage surgeries. Given

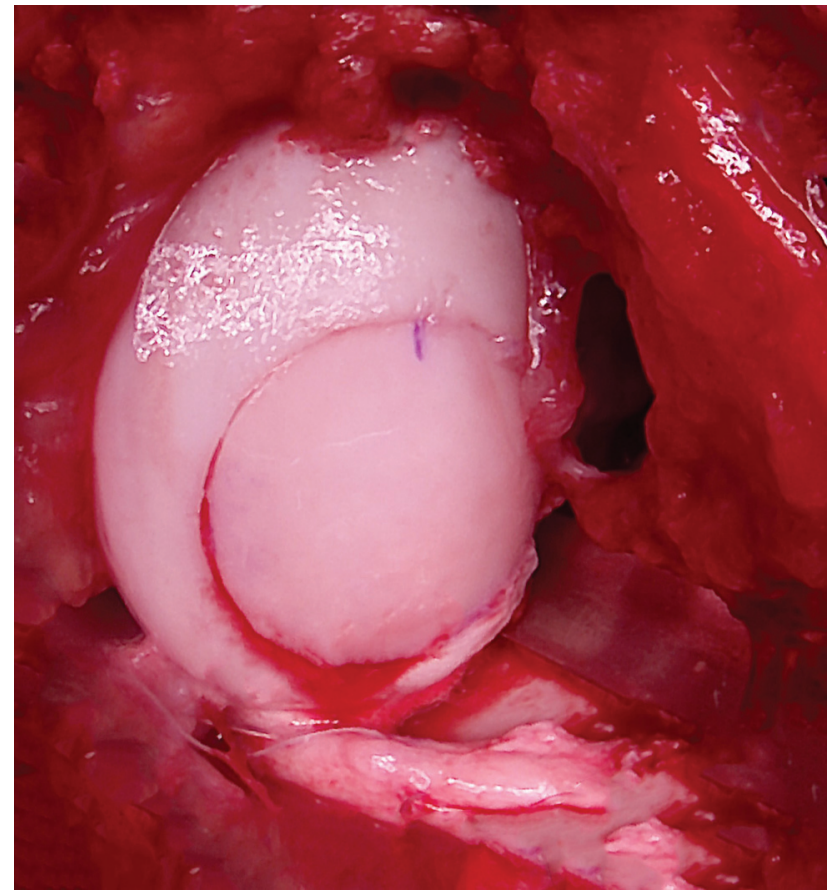

Fig. 2 Photograph of a press-fit osteochondral allograft for a large focal chondral defect of the medial femoral condyle of a left knee. Press-fit osteochondral allografts eliminate the need for additional fixation such as headless screws.

that the allograft source eliminates issues of donor site morbidity, OCAs are useful in the treatment of large FCDs. Furthermore, OCAs can also accommodate lesions with subchondral involvement or bone loss that may exist in revision cases from prior cartilage procedures or OCDs. Surgical techniques for OCA fall into three categories, cylindrical press-fit plugs, oblong press-fit plugs, or free-shell grafts, and are largely dictated by the size and location of the lesion. Plugs are typically obtained and cut from hemicondylar allografts; however, in cases of smaller lesions, fresh precut OCA cores may also be used. ${ }^{56}$ The technical aspects of these procedures have been well documented and described in the literature. The press-fit technique is preferred when possible and eliminates the need for additional fixation such as headless screws, or pins (-Fig. 2). The press-fit approach can also be implemented in a snowman or oblong configuration to adequately cover larger lesions. Instances in which the press-fit technique cannot be implemented include posterior lesions where the joint surface cannot be easily accessed perpendicularly, or lesions of the tibial plateau. In the free-shell technique, a donor graft is matched to the defect site and fixed with screws. Lesions of the plateau can also be addressed through grafting of a size-matched tibial plateau. ${ }^{57}$

\section{Autologous Chondrocyte/Matrix-Associated Autologous Chondrocyte Implantation}

Autologous chondrocyte implantation (ACI) is a two-stage procedure in which chondrocytes are harvested from the knee, typically from the femoral notch or another nonprimary weight-bearing surface, followed by enzymatic 


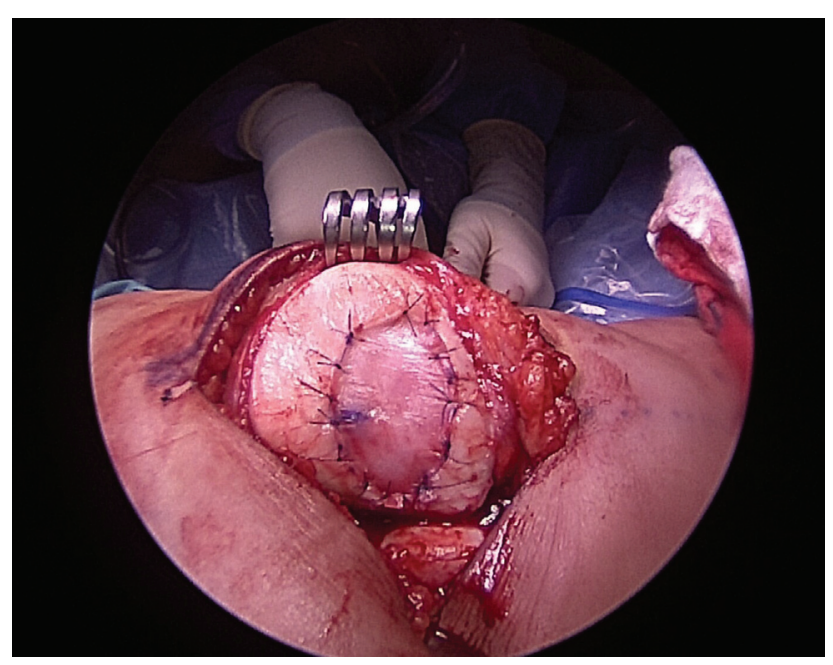

Fig. 3 Medial view of a left knee demonstrating the final product of an autologous chondrocyte implantation repair of a large focal chondral defect of the patella.

processing, culture, and finally, reintroduction at the site of the defect. The chondrocytes are contained within the defect by using a periosteal or collagen membrane patch (-Fig. $\mathbf{3}$ ). Matrix-associated autologous chondrocyte implantation (MACI) represents an evolution of this technique utilizing a porcine collagen membrane scaffold in attempts to apply autologous chondrocytes more evenly, reduce extrusion, and eliminate the need for a patch. ${ }^{58-60}$ It is also postulated that the scaffold may also act as barrier to fibroblast mediated repair. 61

Surgical techniques combining the use of $\mathrm{ACI} / \mathrm{MACI}$ with bone grafting have also been described for patients with large, deep lesions affecting the subchondral bone. ${ }^{62}$ In such cases, subchondral defects can be filled with cancellous bone or bicortical bone graft followed by subsequent autologous chondrocyte implantation. Zellner et al reported on a series of patients treated with this approach in which the mean total size of the defects was $6.7 \mathrm{~cm}^{2}$ (range $=3-14 \mathrm{~cm}^{2}$ ), with a mean depth of $12 \mathrm{~mm} .{ }^{62}$ Such techniques have been proposed to circumvent the need for osteochondral allografts, which may have limited availability and potentially carry additional infectious disease transmission risk.

\section{Minced Cartilage}

The use of minced cartilage dates back to 1983 when it was initially described by Albrecht et al, ${ }^{63}$ demonstrating improved healing of osteochondral defects compared with fibrin. In current practice, minced cartilage procedures commonly utilize allograft articular cartilage from juvenile donors due to chondrocyte density and proliferative capacity (DeNovo Natural Tissue). ${ }^{64,65}$ Intraoperatively, the minced cartilage can be prepared within the defect or using a mold on the back table. The $1-\mathrm{mm}^{3}$ cartilage particles are subsequently inserted into the defect, ensuring they are seated beneath the rim of the defect, followed by sealing with a fibrin glue. The knee is taken through a range of motion to assess stability and ensure the graft site does not sit proud that would result in increased loading and stress. Similar techniques have been described with autograft cartilage (Cartilage Autograft Implantation System, CAIS, Depuy/ Mitek, Raynham, MA) in which articular cartilage is harvested intraoperatively from a minimally load-bearing surface, such as the notch or peripheral trochlea. ${ }^{66}$ The harvested cartilage is then minced and secured to a scaffold with a fibrin sealant. The construct can then be trimmed and transferred into the defect, cartilage-side down, and affixed with biodegradable staple anchors.

\section{Cryopreserved Osteochondral Allografts}

Cyropreserved osteochondral surface allografts are composed of human hyaline articular cartilage and have similar indications to those previously described for $\mathrm{ACI} / \mathrm{MACI}$ in which there is an isolated and contained lesion with minimal subchondral bone loss. ${ }^{67}$ The graft itself serves as a scaffold composed of extracellular matrix in combination with chondrogenic growth factors, proteins, and viable chondrocytes. Some of the currently available products include ProChondrix CR (Allosource, Centennial, CO) and Cartiform (Arthrex Inc., Naples, FL). These grafts have a shelf life of approximately 2 years and can be easily cut to fit the defect and fixed with varying combinations of fibrin glue, sutures, or suture anchors. These products offer additional advantages relative to $\mathrm{ACI} / \mathrm{MACI}$ in that they can be used in a single stage procedure. These techniques can also be used in conjunction with other marrow stimulation techniques such as microfracture.

\section{Augmented Marrow Stimulation}

Other extracellular matrix-based techniques have been described, including BioCartilage (Arthrex Inc., Naples, FL) and Chondro-Gide (Geistlich Pharma AG). The BioCartilage extracellular matrix is developed from cartilage allograft and is comprised of type II collagen, proteoglycans, and other cartilaginous growth factors intended to serve as a scaffold when performed in conjunction with marrow stimulation techniques such as microfracture. Purported advantages include the opportunity for single stage procedures without risk of immunogenicity that can occur from other allograft sources. Chondro-Gide is a membrane composed of collagen $\mathrm{I} / \mathrm{III}$ and is used in combination with microfracture, in a technique described as autologous matrix-induced chondrogenesis (AMIC).

\section{Rehabilitation}

Rehabilitation following surgical treatment of large FCDs is dictated both by the location of the lesion and the procedure performed, with patellofemoral lesions prioritizing weight bearing and protected range of motion and vice versa for tibiofemoral lesions. Additional factors that impact the patient specific postoperative rehabilitation program include body mass index (BMI), preoperative activity level/sport, repair technique, defect location, and concomitant procedures. ${ }^{68}$ In general, patients progress through graduated use of a continuous passive motion (CPM) machine 6 to 8 hours/day for the first 4 to 6 weeks, with 
incremental increases toward full weight-bearing at 6 to 12 weeks. $^{69,70}$

\section{Clinical Outcomes}

\section{Osteochondral Allograft Transplantation}

Outcomes following OCA have been reported for a range of patient ages, BMI, activity levels, sport participation, and concomitant injuries demonstrating good to excellent outcomes and high rates of return to sport. ${ }^{8,9,55,71-78}$ Outcomes data have also highlighted benefits in the form of durability of symptom relief and graft survivorship (-Table 1). A large database study of 1,608 OCA procedures reported a $12.2 \%$ reoperation rate within 2 years. ${ }^{11}$ Similarly, within the literature, survivorship of patellofemoral OCA procedures has been reported to be $87.9 \%$ at 5 years and $77.2 \%$ at 10 years. $^{12}$ Longer term follow-up of smaller samples (58 patients) have demonstrated reported rates of survivorship beyond 20 years, with 91, 84, 69, and 59\% survivorship reported at $10,15,20$, and 25 years, respectively. ${ }^{79}$ As previously mentioned, functional improvements translate to high rates of return to sport. A recent systematic review by Crawford et al reported rates of return to sport of 75 to $82 \%$ from a pooled sample of 772 patients with average defect sizes ranging from 2.4 to $9.6 \mathrm{~cm}^{2} .10$

Importantly, OCA has also been routinely employed as a salvage procedure for prior failed cartilage procedures. Merkely et al performed a matched-group analysis of primary OCA versus OCA revision after failed $\mathrm{ACI}$, demonstrating no significant differences in patient reported outcomes, reoperation, or failure rates at final follow-up, concluding that OCA performs similarly as a revision procedure as it does for the primary treatment of large cartilage defects. ${ }^{80}$ However, it should be noted that equivalent outcomes have not been observed for larger defects requiring snowman grafting. In a small patient series, reoperation and failure rates of snowman grafting have been reported to be as high as 44 and $33 \%$ respectively at $7.7 \pm 5.5$ years, with all failed patients converting to arthroplasty procedures. ${ }^{81}$ Although patients did report improvement in clinical outcomes, failure and reoperations rates for overlapping grafts are higher than those for isolated lesions. Similarly, other patient and allograft characteristics may also increase the risk of failure including higher BMI ( $>35$ ), patient activity, allografts stored $>28$ days, and other baseline comorbidities at the time of surgery. $^{82}$

\section{Autologous Chondrocyte Implantation and Matrix- Associated Autologous Chondrocyte Implantation}

In general, autologous chondrocyte implantation procedures provide significant short- and long-term patient benefits in a variety of patient populations from children and adolescents to middle-age adults. ${ }^{13,14,83,84}$ McNickle et al reported on a series of 140 knees, with a mean single defect size of $4.1 \pm 2.3 \mathrm{~cm}^{2}$ (total average defect(s) area $5.2 \pm 3.5 \mathrm{~cm}^{2}$ ). ${ }^{85}$ In the short term, patients reported high rates of satisfaction (75\%), with $83 \%$ of patients stating that they would have the procedure again, and only $5 \%$ reporting being dissatisfied with the outcome. ${ }^{85}$ Significant improvements were reported for all outcome scales, including Lysholm, International Knee Documentation Committee (IKDC), Knee injury and Osteoarthritis Outcome Score (KOOS) scale, and 12 item short form survey (SF-12). Of note, $15 \%$ of patients required a subsequent reoperation to debride the site of $\mathrm{ACI}$, and $6.4 \%$ were deemed clinical failures, with increasing age and workers' compensation being predictive of inferior outcomes. Beris et al reported similar rates of improvement, with reoperation and clinical failure rates of 11.1 and $4.4 \%$, respectively. ${ }^{86}$ Ebert et al demonstrated comparable results at 2 years following MACI for tibiofemoral and patellofemoral lesions, with concurrent correction of patellar maltracking when indicated. ${ }^{87}$ Success has also been demonstrated in treatment of deeper lesions involving the subchondral bone. Zellner et al reported on patients with large and deep lesions $\left(6.7 \mathrm{~cm}^{2}\right.$, range $=3-14 \mathrm{~cm}^{2}$, mean depth of $\left.12 \mathrm{~mm}\right)$ treated with combined subchondral bone augmentation, also demonstrating good short-term outcomes with significant improvements in IKDC and Cincinnati scores at 3 years, with MRI evidence of subchondral regeneration. ${ }^{62}$

Mid- to long-term follow-up has demonstrated sustained improvements in pain and function. Multiple studies have corroborated rates of survivorship ranging from 74 to $78 \%$ at 5 years and 50 to $74 \%$ at 10 to 12 years. ${ }^{15,16}$ Nawaz et al noted that failure rates were significantly higher (hazard ratio $=4.72$ ) in patients in which $\mathrm{ACI} / \mathrm{MACI}$ was not their first cartilage procedure. ${ }^{15}$ Other factors impacting survivorship of the graft included severity and site of repair, with higher grade lesions, and those located on the patella or medial femoral condyle demonstrating higher rates of failure. Interestingly, size of the lesion did not impact rates of failure, with a reported mean defect size of $409 \mathrm{~mm}^{2}$ (range $=44$ $\left.2,075 \mathrm{~mm}^{2}\right) .{ }^{15}$ Moradi et al reported on 7 - to 14-year outcomes following first generation ACI treatment of lesions with a mean size of $4.3 \pm 2 \mathrm{~cm}^{2}$ (range $=2.5-11.25 \mathrm{~cm}^{2}$ ), noting significant improvement in all outcomes measures, with younger patients, smaller defects, and shorter duration of preoperative symptoms predicting superior outcomes. ${ }^{88}$

Investigations of complication rates demonstrate that $\mathrm{ACI} / \mathrm{MACI}$ is not only efficacious, but a reproducibly safe 2stage procedure. Complication rates following ACI/MACI are less than $1 \%$, and are more commonly associated with earlier generation $\mathrm{ACI}$, including graft hypertrophy, insufficient regeneration or fusion with surrounding cartilage, or repair delamination. $^{14,89,90}$

\section{Minced Cartilage}

Limited data exist regarding the use of minced cartilage for the treatment of large osteochondral defects. Farr et al reported on the results of a small patient series (25 patients), demonstrating symptomatic improvement as early as 3 months and MRI findings demonstrative of good defect filling at 24 months postoperatively following DeNovo NT. ${ }^{91,92}$ Wang et al also reported on the use of DeNovo NT in patellofemoral lesions with a mean follow-up of 3.84 years, demonstrating improvements in IKDC and Knee Outcome Survey-Activities of Daily Living (KOS-ADL), with 69.2\% 


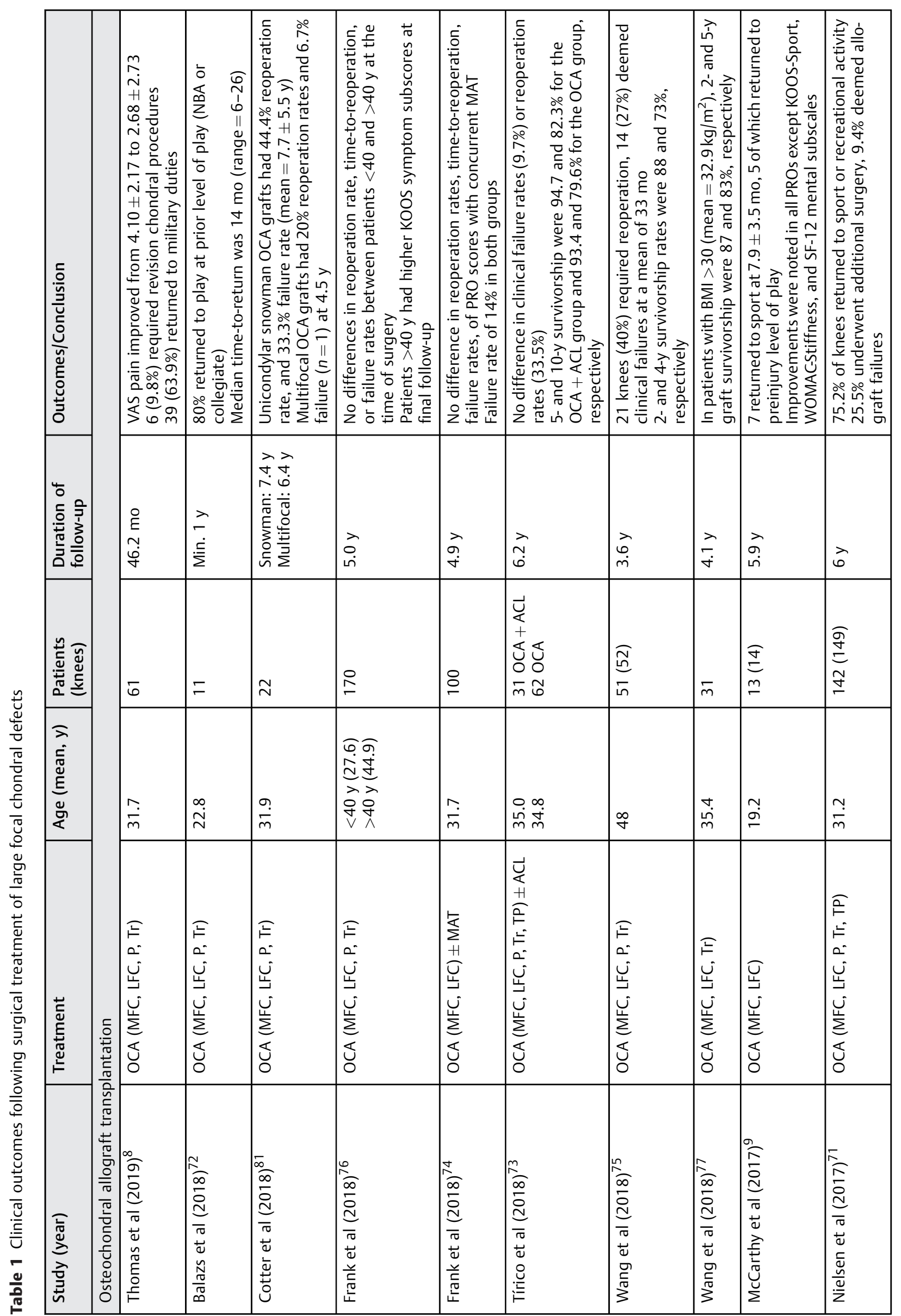




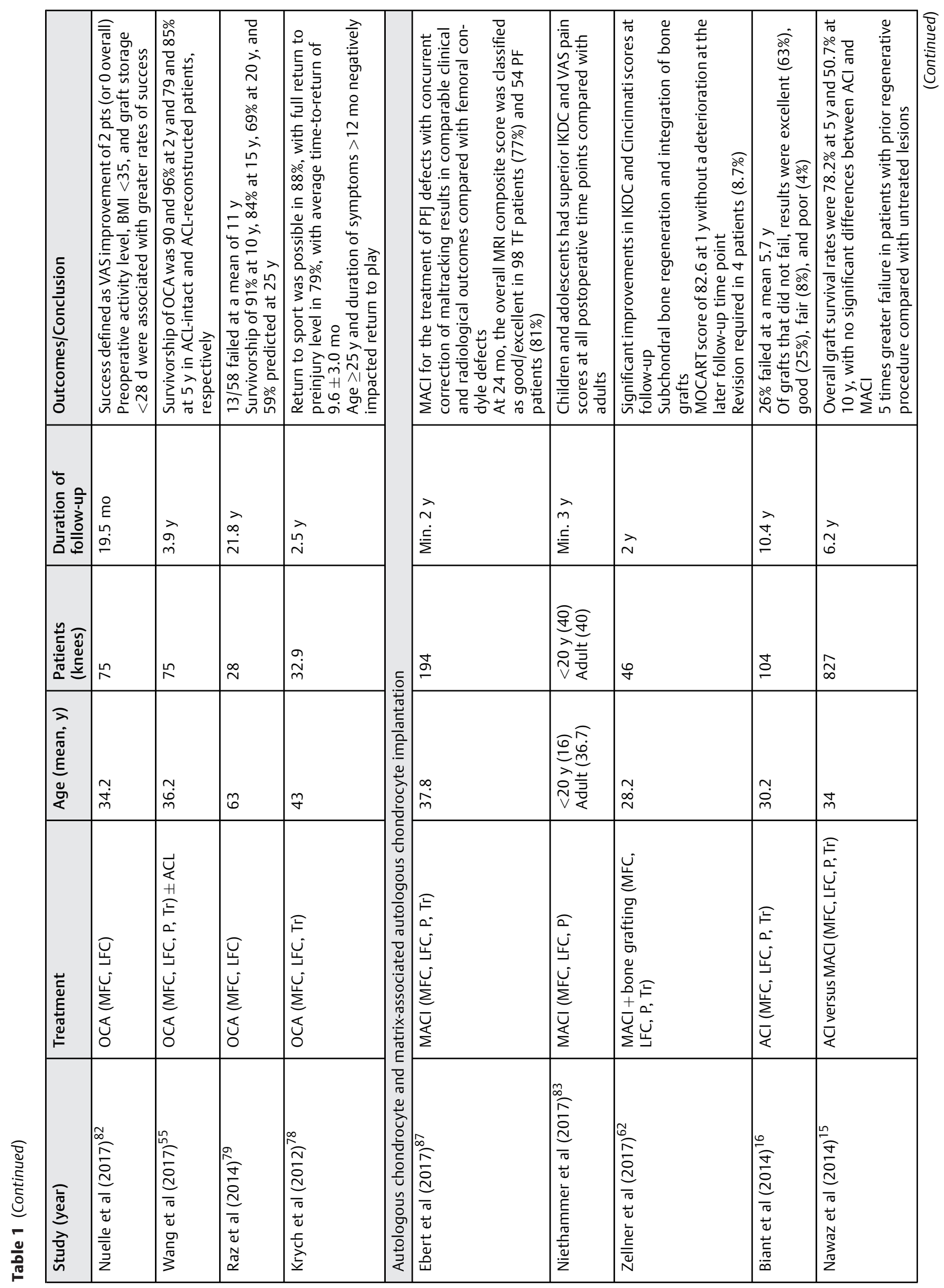




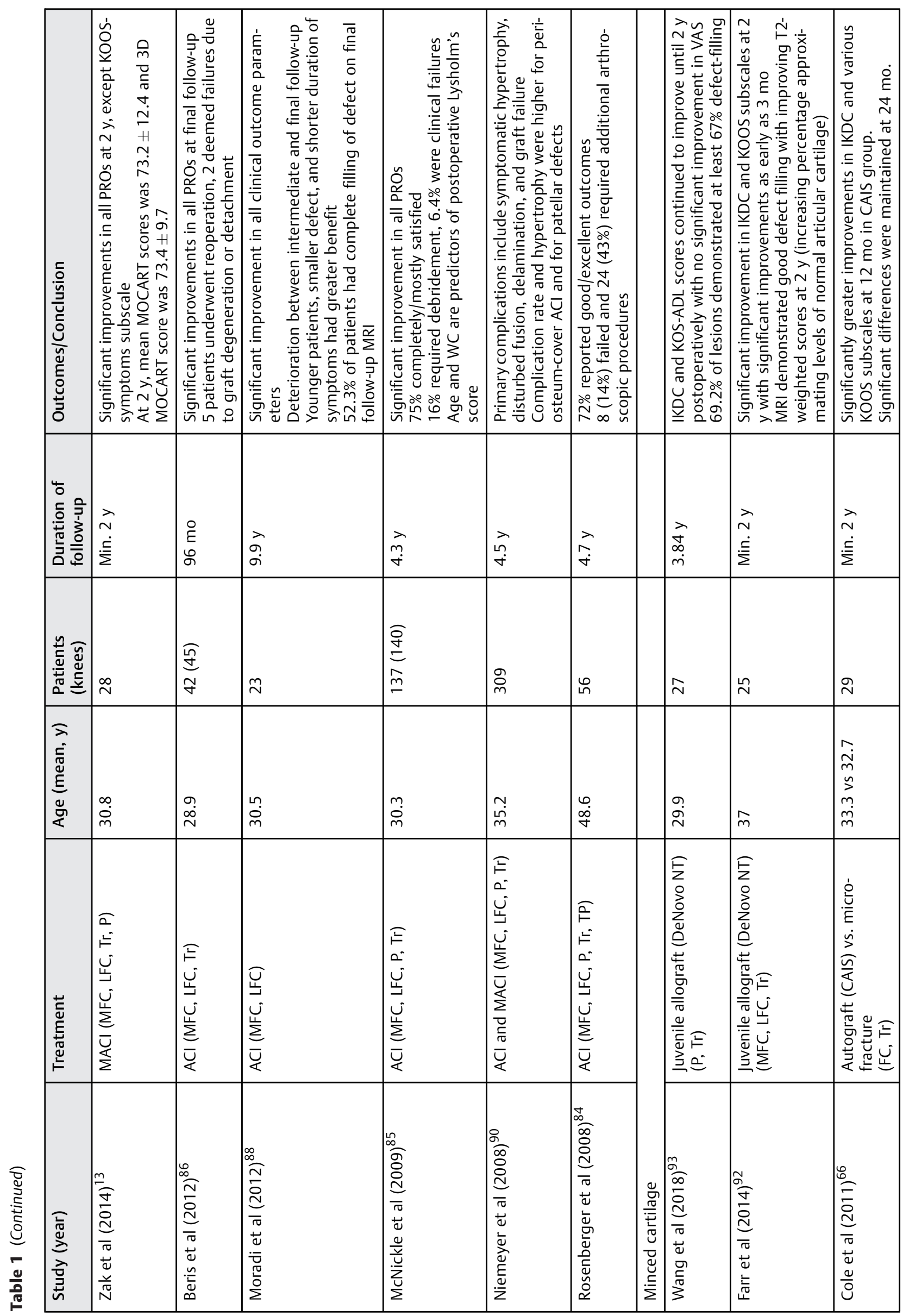



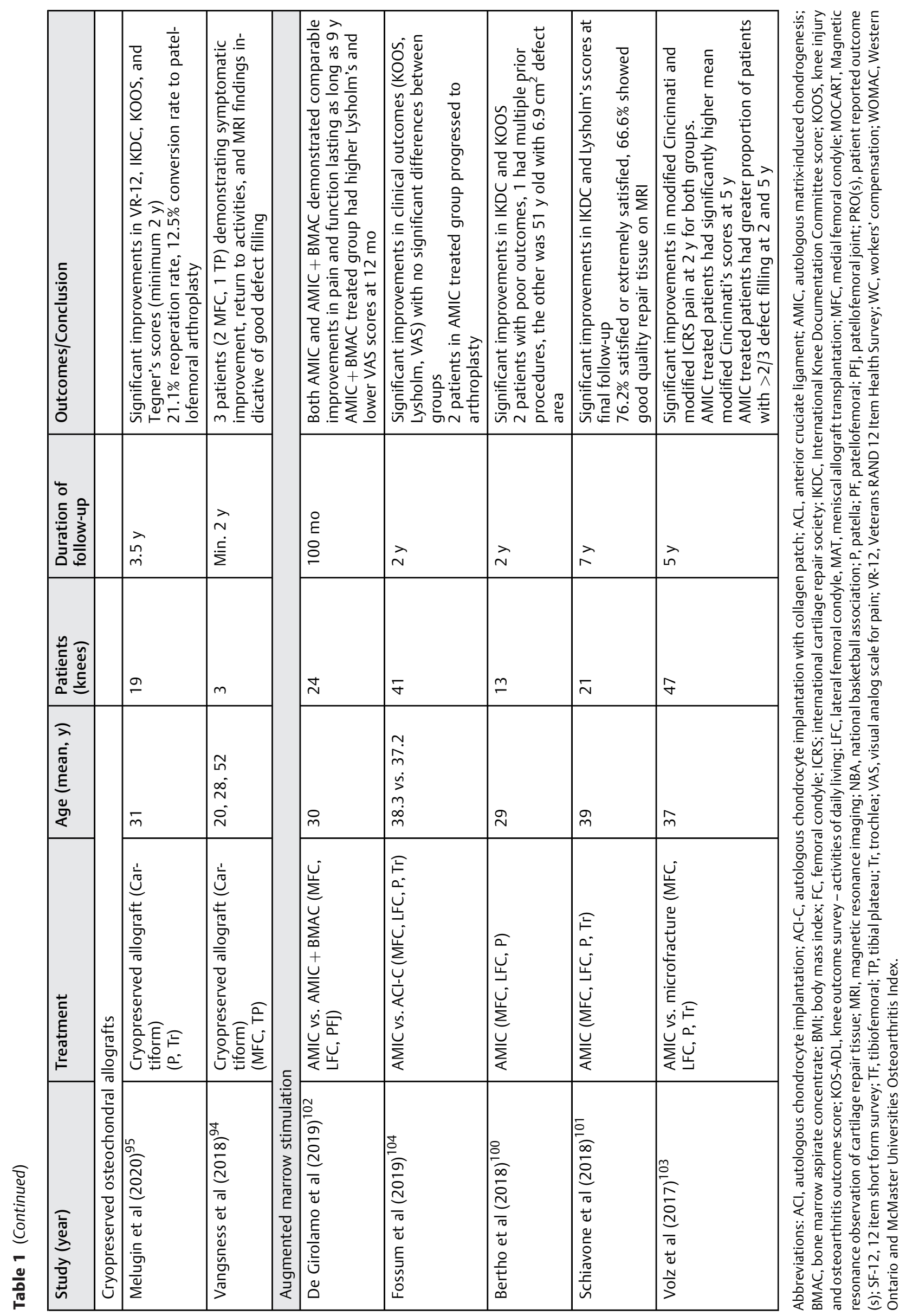
of lesions demonstrating filling greater than two-thirds. ${ }^{93}$ Using autologous cartilage harvest intraoperatively, Cole et al reported on 2-year outcomes after CAIS in a series of 29 patients randomized to either CAIS or microfracture, demonstrating significantly higher IKDC scores beginning at 12 months in the CAIS group compared with microfracture. ${ }^{66}$ Other significant differences were also noted in various KOOS subscales (symptoms and stiffness, pain, activities of daily living, and sports and recreation) at 12 months, and knee-related quality of life at 18 months. All of these differences were maintained at 24 months.

\section{Cryopreserved Osteochondral Allografts}

Given the relative novelty of the technology compared with other surgical techniques, clinical outcomes following implantation of cryopreserved osteochondral allografts are currently limited. Vangsness et al reported on three patients treated with Cartiform (Osiris Therapeutics, Inc., Columbia, $\mathrm{MD}$ ), including two treated for lesions of the medial femoral condyle and one treated for a lesion of the tibial plateau, demonstrating symptomatic improvement, return to activities, and MRI findings indicative of good defect filling out to 2 years postopeatively. ${ }^{94}$ Melugin et al reported on a series of 19 patients with patellofemoral defects treated with Cartiform (Osiris Therapeutics, Inc., Columbia, MD). Patients demonstrated significant improvements in VR-12, IKDC, KOOS, and Tegner's scores at a minimum of 24 months follow-up. However, there was a $21.1 \%$ reoperation rate and $12.5 \%$ conversion rate to patellofemoral arthroplasty. ${ }^{95}$

\section{Augmented Marrow Stimulation}

Outcomes after surgery with extracellular matrix scaffolds are largely limited to animal models and case series. Several techniques are described in the literature of combined BioCartilage and microfracture techniques; however, outcome data are limited. ${ }^{96-98}$ Other techniques, such as AMIC utilizing the Chondro-Gide collagen membrane have more clinical outcomes data, demonstrating significant improvements in clinical and functional outcomes based on systematic review. ${ }^{99}$ Bertho et al reported on preliminary results in 13 patients with a mean defect area of $3.7 \mathrm{~cm}^{2}$ treated with AMIC. At a minimum of 1-year follow-up, patients reported significant improvements in IKDC and KOOS scores. ${ }^{100}$ Schiavone Panni et al reported on a series of 21 patients treated with AMIC for full thickness lesions $>2 \mathrm{~cm}^{2}$, demonstrating significant improvements in Lysholm and IKDC with an average of 7 years of follow-up. The same study also reported $76.2 \%$ patient satisfaction rates with $66.6 \%$ of patient demonstrating reduced defect size and subchondral edema on MRI. ${ }^{101}$ Another study performed by de Girolamo et al with a similar length of follow-up suggested that bone marrow aspirate concentrate (BMAC) may help augment functional improvements and pain relief in the short term (12 months). ${ }^{102}$ Autologous matrix-induced chondrogenesis has also been compared with other treatments in multiple randomized trials. Volz et al compared AMIC to microfracture in a series of 47 patients with a mean defect size of $3.6 \pm 1.6 \mathrm{~cm}^{2} .{ }^{103}$ At 2 years, all groups demonstrated signifi- cant improvements in modified Cincinnati score and modified ICRS score for pain. At 5 years, improvements were still noted for all groups; however, AMIC-treated subjects had significantly higher Modified Cincinnati scores. On 2- and 5year MRI, AMIC-treated groups also had a greater proportion of subjects with $>2 / 3$ defect filling. In another randomized trial, Fossum et al compared 2-year outcomes in 41 patients treated with either AMIC or ACI covered with a collagen patch with mean total defect sizes of $5.2 \pm 2.4$ and $4.9 \pm 4.4 \mathrm{~cm}^{2}$, respectively. ${ }^{104}$ At 2-year follow-up, both groups demonstrated significant improvements in clinical scores (KOOS, Lysholm, and VAS pain) with no significant differences between groups with respect to the magnitude of improvement; however, two patients in the AMIC group progressed to arthroplasty by 2-year follow-up.

\section{Conclusion}

Focal chondral defects (FCDs) of the knee with accompanying pain and dysfunction can be debilitating conditions affecting young active patients. Optimal outcomes are dependent on complete integration of clinical care from a timely and accurate diagnosis to selection of a patient- and defectspecific surgical intervention, through postoperative rehabilitation and return to activities. For lesions that involve a larger chondral area, a variety of well-established complex restorative procedures exist such as OCA and $\mathrm{ACI} / \mathrm{MACI}$, in addition to other emerging resurfacing technologies. Outcomes data have demonstrated reproducible results including long-term relief of symptoms and return to activities. Given the array of treatment options, the challenge lies in determining which intervention or combination of interventions is most appropriate, given patient- and defect-specific characteristics, while considering important comorbidities such as mechanical alignment, meniscal pathology, and ligamentous status.

\section{Funding}

None.

\section{Conflict of Interest}

J.C. is a board or committee member of the American Orthopaedic Society for Sports Medicine (AOSSM), Arthroscopy Association of North America (AANA), and the International Society of Arthroscopy, Knee Surgery, and Orthopaedic Sports Medicine (ISAKOS); and is a paid consultant for Arthrex, Inc, CONMED Linvatec, Ossur, and Smith \& Nephew. A.B.Y. receives research support from Arthrex, Inc, Organogenesis, and Vericel; is an unpaid consultant for Patient IQ Smith \& Nephew, and Sparta Biomedical; is a paid consultant for CONMED Linvatec, JRF Ortho, and Olympus; and receives stock or stock options from Patient IQ. J.F. receives research support from Active Implants, Arthrex, Inc, Episurf, Fidia, JRF Ortho, Moximed, Novartis, Organogenesis, Samumed, Inc, Vericel, and ZimmerBiomet; is a paid consultant for Aesculap/B.Braun, Cartiheal, Cook Biotech, Exactech, Moximed, Inc, Organogenesis, Regentis, Samumed, Inc, 
and ZKR orthopedics; is on the editorial or governing board of the American Journal of Orthopedics, and Cartialge; is a paid presenter or speaker for Arthrex, Inc, Moximed, Inc, Organogenesis, and Vericel; receives IP royalties from Arthrex, Inc, Biopoly, LLC, and Organogenesis; receives stock or stock options from MedShape, Inc, and Ortho Regenerative Tech; and receives publishing royalties, financial or material support from Springer, and Thieme Medical Publishers, Inc.

\section{References}

1 Flanigan DC, Harris JD, Trinh TQ Siston RA, Brophy RH. Prevalence of chondral defects in athletes' knees: a systematic review. Med Sci Sports Exerc 2010;42(10):1795-1801

2 Arøen A, Løken S, Heir S, et al. Articular cartilage lesions in 993 consecutive knee arthroscopies. Am J Sports Med 2004;32(01): 211-215

3 Curl WW, Krome J, Gordon ES, Rushing J, Smith BP, Poehling GG. Cartilage injuries: a review of 31,516 knee arthroscopies. Arthroscopy 1997;13(04):456-460

4 Hjelle K, Solheim E, Strand T, Muri R, Brittberg M. Articular cartilage defects in 1,000 knee arthroscopies. Arthroscopy 2002; 18(07):730-734

5 Zamber RW, Teitz CC, McGuire DA, Frost JD, Hermanson BK. Articular cartilage lesions of the knee. Arthroscopy 1989;5(04): 258-268

6 Davies-Tuck ML, Wluka AE, Wang Y, et al. The natural history of cartilage defects in people with knee osteoarthritis. Osteoarthritis Cartilage 2008;16(03):337-342

7 Behery O, Siston RA, Harris JD, Flanigan DC. Treatment of cartilage defects of the knee: expanding on the existing algorithm. Clin J Sport Med 2014;24(01):21-30

8 Thomas D, Shaw KA, Waterman BR. Outcomes after fresh osteochondral allograft transplantation for medium to large chondral defects of the knee. Orthop J Sports Med 2019;7(03):232596 7119832299

9 McCarthy MA, Meyer MA, Weber AE, et al. Can competitive athletes return to high-level play after osteochondral allograft transplantation of the knee? Arthroscopy 2017;33(09):1712-1717

10 Crawford ZT, Schumaier AP, Glogovac G, Grawe BM. Return to sport and sports-specific outcomes after osteochondral allograft transplantation in the knee: a systematic review of studies with at least 2 years' mean follow-up. Arthroscopy 2019;35(06): 1880-1889

11 Frank RM, McCormick F, Rosas S, et al. Reoperation rates after cartilage restoration procedures in the knee: analysis of a large US commercial database. Am J Orthop 2018;47(06). Doi: 10.12788/ajo.2018.0040

12 Chahla J, Sweet MC, Okoroha KR, et al. Osteochondral allograft transplantation in the patellofemoral joint: a systematic review. Am J Sports Med 2018:363546518814236

13 Zak L, Albrecht C, Wondrasch B, et al. Results 2 years after matrixassociated autologous chondrocyte transplantation using the novocart 3D scaffold: an analysis of clinical and radiological data. Am J Sports Med 2014;42(07):1618-1627

14 Harris JD, Siston RA, Pan X, Flanigan DC. Autologous chondrocyte implantation: a systematic review. J Bone Joint Surg Am 2010;92 (12):2220-2233

15 Nawaz SZ, Bentley G, Briggs TW, et al. Autologous chondrocyte implantation in the knee: mid-term to long-term results. J Bone Joint Surg Am 2014;96(10):824-830

16 Biant LC, Bentley G, Vijayan S, Skinner JA, Carrington RW. Longterm results of autologous chondrocyte implantation in the knee for chronic chondral and osteochondral defects. Am J Sports Med 2014;42(09):2178-2183
17 Widuchowski W, Widuchowski J, Faltus R, et al. Long-term clinical and radiological assessment of untreated severe cartilage damage in the knee: a natural history study. Scand J Med Sci Sports 2011;21(01):106-110

18 Houck DA, Kraeutler MJ, Belk JW, Frank RM, McCarty EC, Bravman JT. Do focal chondral defects of the knee increase the risk for progression to osteoarthritis? A review of the literature. Orthop J Sports Med 2018;6(10):2325967118801931

19 Dye SF. The pathophysiology of patellofemoral pain: a tissue homeostasis perspective. Clin Orthop Relat Res 2005;(436): $100-110$

20 Gomoll AH, Minas T, Farr J, Cole BJ. Treatment of chondral defects in the patellofemoral joint. J Knee Surg 2006;19(04):285-295

21 Mall NA, Harris JD, Cole BJ. Clinical evaluation and preoperative planning of articular cartilage lesions of the knee. J Am Acad Orthop Surg 2015;23(10):633-640

22 Rosenberg TD, Paulos LE, Parker RD, Coward DB, Scott SM. The forty-five-degree posteroanterior flexion weight-bearing radiograph of the knee. J Bone Joint Surg Am 1988;70(10):1479-1483

23 Godin JA, Hussain ZB, Sanchez A, et al. Multicompartmental osteochondral allografts of knee and concomitant high tibial osteotomy. Arthrosc Tech 2017;6(05):e1959-e1965

24 Samitier G, Alentorn-Geli E, Taylor DC, et al. Meniscal allograft transplantation. Part 1: systematic review of graft biology, graft shrinkage, graft extrusion, graft sizing, and graft fixation. Knee Surg Sports Traumatol Arthrosc 2015;23(01):310-322

25 Gomoll AH, Yoshioka H, Watanabe A, Dunn JC, Minas T. Preoperative measurement of cartilage defects by MRI underestimates lesion size. Cartilage 2011;2(04):389-393

26 O'Connor MA, Palaniappan M, Khan N, Bruce CE. Osteochondritis dissecans of the knee in children: a comparison of MRI and arthroscopic findings. J Bone Joint Surg Br 2002;84(02):258-262

27 Gillis A, Bashir A, McKeon B, Scheller A, Gray ML, Burstein D. Magnetic resonance imaging of relative glycosaminoglycan distribution in patients with autologous chondrocyte transplants. Invest Radiol 2001;36(12):743-748

28 Potter HG, Foo LF. Magnetic resonance imaging of articular cartilage: trauma, degeneration, and repair. Am J Sports Med 2006;34(04):661-677

29 Stelzeneder D, Shetty AA, Kim SJ, et al. Repair tissue quality after arthroscopic autologous collagen-induced chondrogenesis (ACIC) assessed via T2* mapping. Skeletal Radiol 2013;42(12): 1657-1664

30 Tiderius CJ, Tjörnstrand J, Akeson P, Södersten K, Dahlberg L, Leander P. Delayed gadolinium-enhanced MRI of cartilage (dGEMRIC): intra- and interobserver variability in standardized drawing of regions of interest. Acta Radiol 2004;45(06):628-634

31 Young AA, Stanwell P, Williams A, et al. Glycosaminoglycan content of knee cartilage following posterior cruciate ligament rupture demonstrated by delayed gadolinium-enhanced magnetic resonance imaging of cartilage (dGEMRIC): a case report. J Bone Joint Surg Am 2005;87(12):2763-2767

32 Kurkijärvi JE, Nissi MJ, Kiviranta I, Jurvelin JS, Nieminen MT. Delayed gadolinium-enhanced MRI of cartilage (dGEMRIC) and T2 characteristics of human knee articular cartilage: topographical variation and relationships to mechanical properties. Magn Reson Med 2004;52(01):41-46

33 Shelbourne KD, Jari S, Gray T. Outcome of untreated traumatic articular cartilage defects of the knee: a natural history study. J Bone Joint Surg Am 2003;85-A(Suppl 2):8-16

34 Murray JR, Chitnavis J, Dixon P, et al. Osteochondritis dissecans of the knee; long-term clinical outcome following arthroscopic debridement. Knee 2007;14(02):94-98

35 Messner $\mathrm{K}$, Maletius $\mathrm{W}$. The long-term prognosis for severe damage to weight-bearing cartilage in the knee: a 14-year clinical and radiographic follow-up in 28 young athletes. Acta Orthop Scand 1996;67(02):165-168 
36 Henn RF III, Gomoll AH. A review of the evaluation and management of cartilage defects in the knee. Phys Sportsmed 2011;39 (01):101-107

37 Everhart JS, Abouljoud MM, Kirven JC, Flanigan DC. Full-thickness cartilage defects are important independent predictive factors for progression to total knee arthroplasty in older adults with minimal to moderate osteoarthritis: data from the osteoarthritis initiative. J Bone Joint Surg Am 2019;101(01):56-63

38 Ogura T, Merkely G, Bryant T, Winalski CS, Minas T. Autologous chondrocyte implantation "segmental-sandwich" technique for deep osteochondral defects in the knee: clinical outcomes and correlation with magnetic resonance imaging findings. Orthop J Sports Med 2019;7(05):2325967119847173

39 Ferruzzi A, Buda R, Cavallo M, Timoncini A, Natali S, Giannini S. Cartilage repair procedures associated with high tibial osteotomy in varus knees: clinical results at 11 years' follow-up. Knee 2014;21(02):445-450

40 Knutsen G, Drogset JO, Engebretsen L, et al. A randomized trial comparing autologous chondrocyte implantation with microfracture. Findings at five years. J Bone Joint Surg Am 2007;89 (10):2105-2112

41 Knutsen G, Drogset JO, Engebretsen L, et al. A randomized multicenter trial comparing autologous chondrocyte implantation with microfracture: long-term follow-up at 14 to 15 years. J Bone Joint Surg Am 2016;98(16):1332-1339

42 Ekman E, Mäkelä K, Kohonen I, Hiltunen A, Itälä A Favourable long-term functional and radiographical outcome after osteoautograft transplantation surgery of the knee: a minimum 10-year follow-up. Knee Surg Sports Traumatol Arthrosc 2018;26(12): 3560-3565

43 Gudas R, Kalesinskas RJ, Kimtys V, et al. A prospective randomized clinical study of mosaic osteochondral autologous transplantation versus microfracture for the treatment of osteochondral defects in the knee joint in young athletes. Arthroscopy 2005;21(09):1066-1075

44 Gudas R, Gudaite A, Pocius A, et al. Ten-year follow-up of a prospective, randomized clinical study of mosaic osteochondral autologous transplantation versus microfracture for the treatment of osteochondral defects in the knee joint of athletes. Am J Sports Med 2012;40(11):2499-2508

45 Ulstein S, Årøen A, Røtterud JH, Løken S, Engebretsen L, Heir S. Microfracture technique versus osteochondral autologous transplantation mosaicplasty in patients with articular chondral lesions of the knee: a prospective randomized trial with longterm follow-up. Knee Surg Sports Traumatol Arthrosc 2014;22 (06):1207-1215

46 Rue JP, Yanke AB, Busam ML, McNickle AG, Cole BJ. Prospective evaluation of concurrent meniscus transplantation and articular cartilage repair: minimum 2-year follow-up. Am J Sports Med 2008;36(09):1770-1778

47 Frank RM, Cole BJ. Meniscus transplantation. Curr Rev Musculoskelet Med 2015;8(04):443-450

48 Abrams GD, Hussey KE, Harris JD, Cole BJ. Clinical results of combined meniscus and femoral osteochondral allograft transplantation: minimum 2-year follow-up. Arthroscopy 2014;30 (08):964-70.e1

49 Farr J, Rawal A, Marberry KM. Concomitant meniscal allograft transplantation and autologous chondrocyte implantation: minimum 2-year follow-up. Am J Sports Med 2007;35(09):1459-1466

50 Marti RK, Verhagen RA, Kerkhoffs GM, Moojen TM. Proximal tibial varus osteotomy. Indications, technique, and five to twenty-one-year results. J Bone Joint Surg Am 2001;83(02):164-170

51 Bode G, Schmal H, Pestka JM, Ogon P, Südkamp NP, Niemeyer P. A non-randomized controlled clinical trial on autologous chondrocyte implantation (ACI) in cartilage defects of the medial femoral condyle with or without high tibial osteotomy in patients with varus deformity of less than $5^{\circ}$. Arch Orthop Trauma Surg 2013;133(01):43-49
52 Kahlenberg CA, Nwachukwu BU, Hamid KS, Steinhaus ME, Williams RJ III. Analysis of outcomes for high tibial osteotomies performed with cartilage restoration techniques. Arthroscopy 2017;33(02):486-492

53 Farr J. Autologous chondrocyte implantation improves patellofemoral cartilage treatment outcomes. Clin Orthop Relat Res 2007;463(463):187-194

54 Cotter EJ, Waterman BR, Kelly MP, Wang KC, Frank RM, Cole BJ. Multiple osteochondral allograft transplantation with concomitant tibial tubercle osteotomy for multifocal chondral disease of the knee. Arthrosc Tech 2017;6(04):e1393-e1398

55 Wang D, Eliasberg CD, Wang T, et al. Similar outcomes after osteochondral allograft transplantation in anterior cruciate ligament-intact and -reconstructed knees: a comparative matched-group analysis with minimum 2-year follow-up. Arthroscopy 2017;33(12):2198-2207

56 Jones KJ, Mosich GM, Williams RJ. Fresh precut osteochondral allograft core transplantation for the treatment of femoral cartilage defects. Arthrosc Tech 2018;7(08):e791-e795

57 Godin JA, Frangiamore S, Chahla J, Cinque ME, DePhillipo NN, LaPrade RF. Tibial allograft transfer for medial tibial plateau resurfacing. Arthrosc Tech 2017;6(03):e661-e665

58 Bartlett W, Skinner JA, Gooding CR, et al. Autologous chondrocyte implantation versus matrix-induced autologous chondrocyte implantation for osteochondral defects of the knee: a prospective, randomised study. J Bone Joint Surg $\mathrm{Br} 2005 ; 87$ (05):640-645

59 Sohn DH, Lottman LM, Lum LY, et al. Effect of gravity on localization of chondrocytes implanted in cartilage defects. Clin Orthop Relat Res 2002;(394):254-262

60 Gikas PD, Bayliss L, Bentley G, Briggs TW. An overview of autologous chondrocyte implantation. J Bone Joint Surg $\mathrm{Br}$ 2009;91(08):997-1006

61 Frenkel SR, Toolan B, Menche D, Pitman MI, Pachence JM. Chondrocyte transplantation using a collagen bilayer matrix for cartilage repair. J Bone Joint Surg Br 1997;79(05):831-836

62 Zellner J, Grechenig S, Pfeifer CG, et al. Clinical and radiological regeneration of large and deep osteochondral defects of the knee by bone augmentation combined with matrix-guided autologous chondrocyte transplantation. Am J Sports Med 2017;45 (13):3069-3080

63 Albrecht F, Roessner A, Zimmermann E. Closure of osteochondral lesions using chondral fragments and fibrin adhesive. Arch Orthop Trauma Surg 1983;101(03):213-217

64 Bonasia DE, Martin JA, Marmotti A, et al. Cocultures of adult and juvenile chondrocytes compared with adult and juvenile chondral fragments: in vitro matrix production. Am J Sports Med 2011;39(11):2355-2361

65 McCormick F, Yanke A, Provencher MT, Cole BJ. Minced articular cartilage-basic science, surgical technique, and clinical application. Sports Med Arthrosc Rev 2008;16(04):217-220

66 Cole BJ, Farr J, Winalski CS, et al. Outcomes after a single-stage procedure for cell-based cartilage repair: a prospective clinical safety trial with 2-year follow-up. Am J Sports Med 2011;39(06): 1170-1179

67 Woodmass JM, Melugin HP, Wu IT, Saris DBF, Stuart MJ, Krych AJ. Viable osteochondral allograft for the treatment of a full-thickness cartilage defect of the patella. Arthrosc Tech 2017;6(05): e1661-e1665

68 Mithoefer K, Hambly K, Logerstedt D, Ricci M, Silvers H, Della Villa S. Current concepts for rehabilitation and return to sport after knee articular cartilage repair in the athlete. J Orthop Sports Phys Ther 2012;42(03):254-273

69 Seo S-S, Kim C-W, Jung D-W. Management of focal chondral lesion in the knee joint. Knee Surg Relat Res 2011;23(04): 185-196

70 Jones DG, Peterson L. Autologous chondrocyte implantation. Instr Course Lect 2007;56:429-445 
71 Nielsen ES, McCauley JC, Pulido PA, Bugbee WD. Return to sport and recreational activity after osteochondral allograft transplantation in the knee. Am J Sports Med 2017;45(07):1608-1614

72 Balazs GC, Wang D, Burge AJ, Sinatro AL, Wong AC, Williams RJ III. Return to play among elite basketball players after osteochondral allograft transplantation of full-thickness cartilage lesions. Orthop J Sports Med 2018;6(07):2325967118786941

73 Tírico LEP, McCauley JC, Pulido PA, Bugbee WD. Does anterior cruciate ligament reconstruction affect the outcome of osteochondral allograft transplantation?: a matched cohort study with a mean follow-up of 6 years Am J Sports Med 2018;46(08):1836-1843

74 Frank RM, Lee S, Cotter EJ, Hannon CP, Leroux T, Cole BJ. Outcomes of osteochondral allograft transplantation with and without concomitant meniscus allograft transplantation: a comparative matched group analysis. Am J Sports Med 2018;46(03):573-580

75 Wang D, Kalia V, Eliasberg CD, et al. Osteochondral allograft transplantation of the knee in patients aged 40 years and older. Am J Sports Med 2018;46(03):581-589

76 Frank RM, Cotter EJ, Lee S, Poland S, Cole BJ. Do outcomes of osteochondral allograft transplantation differ based on age and sex?: a comparative matched group analysis Am J Sports Med 2018;46(01):181-191

77 Wang D, Rebolledo BJ, Dare DM, et al. Osteochondral allograft transplantation of the knee in patients with an elevated body mass index. Cartilage 2018:1947603518754630

78 Krych AJ, Robertson CM, Williams RJ IIICartilage Study Group. Return to athletic activity after osteochondral allograft transplantation in the knee. Am J Sports Med 2012;40(05):1053-1059

79 Raz G, Safir OA, Backstein DJ, Lee PT, Gross AE. Distal femoral fresh osteochondral allografts: follow-up at a mean of twentytwo years. J Bone Joint Surg Am 2014;96(13):1101-1107

80 Merkely G, Ogura T, Ackermann J, Barbieri Mestriner A, Gomoll $\mathrm{AH}$. Clinical outcomes after revision of autologous chondrocyte implantation to osteochondral allograft transplantation for large chondral defects: a comparative matched-group analysis. Cartilage 2019:1947603519833136

81 Cotter EJ, Hannon CP, Christian DR, et al. Clinical outcomes of multifocal osteochondral allograft transplantation of the knee: an analysis of overlapping grafts and multifocal lesions. Am J Sports Med 2018;46(12):2884-2893

82 Nuelle CW, Nuelle JA, Cook JL, Stannard JP. Patient factors, donor age, and graft storage duration affect osteochondral allograft outcomes in knees with or without comorbidities. J Knee Surg 2017;30(02):179-184

83 Niethammer TR, Holzgruber M, Gülecyüz MF, Weber P, Pietschmann MF, Müller PE. Matrix based autologous chondrocyte implantation in children and adolescents: a match paired analysis in a follow-up over three years post-operation. Int Orthop 2017;41(02):343-350

84 Rosenberger RE, Gomoll AH, Bryant T, Minas T. Repair of large chondral defects of the knee with autologous chondrocyte implantation in patients 45 years or older. Am J Sports Med 2008;36(12):2336-2344

85 McNickle AG, L'Heureux DR, Yanke AB, Cole BJ. Outcomes of autologous chondrocyte implantation in a diverse patient population. Am J Sports Med 2009;37(07):1344-1350

86 Beris AE, Lykissas MG, Kostas-Agnantis I, Manoudis GN. Treatment of full-thickness chondral defects of the knee with autologous chondrocyte implantation: a functional evaluation with long-term follow-up. Am J Sports Med 2012;40(03):562-567

87 Ebert JR, Schneider A, Fallon M, Wood DJ, Janes GC. A comparison of 2-year outcomes in patients undergoing tibiofemoral or patellofemoral matrix-induced autologous chondrocyte implantation. Am J Sports Med 2017;45(14):3243-3253

88 Moradi B, Schönit E, Nierhoff C, et al. First-generation autologous chondrocyte implantation in patients with cartilage defects of the knee: 7 to 14 years' clinical and magnetic resonance imaging follow-up evaluation. Arthroscopy 2012;28(12):1851-1861

89 Gowd AK, Cvetanovich GL, Liu JN, et al. Management of chondral lesions of the knee: analysis of trends and short-term complications using the national surgical quality improvement program database. Arthroscopy 2019;35(01):138-146

90 Niemeyer P, Pestka JM, Kreuz PC, et al. Characteristic complications after autologous chondrocyte implantation for cartilage defects of the knee joint. Am J Sports Med 2008;36(11):2091-2099

91 Farr J, Cole BJ, Sherman S, Karas V. Particulated articular cartilage: CAIS and DeNovo NT. J Knee Surg 2012;25(01):23-29

92 Farr J, Tabet SK, Margerrison E, Cole BJ. Clinical, radiographic, and histological outcomes after cartilage repair with particulated juvenile articular cartilage: a 2-year prospective study. Am J Sports Med 2014;42(06):1417-1425

93 Wang T, Belkin NS, Burge AJ, et al. Patellofemoral cartilage lesions treated with particulated juvenile allograft cartilage: a prospective study with minimum 2-year clinical and magnetic resonance imaging outcomes. Arthroscopy 2018;34(05):1498-1505

94 Vangsness CT Jr, Higgs G, Hoffman JK, et al. Implantation of a novel cryopreserved viable osteochondral allograft for articular cartilage repair in the knee. J Knee Surg 2018;31(06):528-535

95 Melugin HP, Ridley TJ, Bernard CD, et al. Prospective outcomes of cryopreserved osteochondral allograft for patellofemoral cartilage defects at minimum 2-year follow-up. Cartilage 2020: 1947603520903420

96 Carter AH, Guttierez N, Subhawong TK, et al. MR imaging of BioCartilage augmented microfracture surgery utilizing 2D MOCART and KOOS scores. J Clin Orthop Trauma 2018;9(02): 146-152

97 Wang KC, Frank RM, Cotter EJ, Christian DR, Cole BJ. Arthroscopic management of isolated tibial plateau defect with microfracture and micronized allogeneic cartilage-platelet-rich plasma adjunct. Arthrosc Tech 2017;6(05):e1613-e1618

98 Schallmo MS, Marquez-Lara A, Luo TD, Rosas S, Stubbs AJ. Arthroscopic treatment of hip chondral defect with microfracture and platelet-rich plasma-infused micronized cartilage allograft augmentation. Arthrosc Tech 2018;7(04):e361-e365

99 Steinwachs MR, Gille J, Volz M, et al. Systematic review and metaanalysis of the clinical evidence on the use of autologous matrixinduced chondrogenesis in the knee. Cartilage 2019: 1947603519870846

100 Bertho P, Pauvert A, Pouderoux T, Robert HOrthopaedics and Traumatology Society of Western France (SOO) Treatment of large deep osteochondritis lesions of the knee by autologous matrix-induced chondrogenesis (AMIC): Preliminary results in 13 patients. Orthop Traumatol Surg Res 2018;104(05):695-700

101 Schiavone Panni A, Del Regno C, Mazzitelli G, D’Apolito R, Corona $\mathrm{K}$, Vasso M. Good clinical results with autologous matrix-induced chondrogenesis (Amic) technique in large knee chondral defects. Knee Surg Sports Traumatol Arthrosc 2018;26(04):1130-1136

102 de Girolamo L, Schönhuber H, Viganò M, et al. Autologous matrix-induced chondrogenesis (AMIC) and AMIC enhanced by autologous concentrated bone marrow aspirate (BMAC) allow for stable clinical and functional improvements at up to 9 years follow-up: results from a randomized controlled study. J Clin Med 2019;8(03):E392

103 Volz M, Schaumburger J, Frick H, Grifka J, Anders S. A randomized controlled trial demonstrating sustained benefit of autologous matrix-induced chondrogenesis over microfracture at five years. Int Orthop 2017;41(04):797-804

104 Fossum V, Hansen AK, Wilsgaard T, Knutsen G. Collagen-covered autologous chondrocyte implantation versus autologous matrixinduced chondrogenesis: a randomized trial comparing 2 methods for repair of cartilage defects of the knee. Orthop J Sports Med 2019;7(09):2325967119868212 